\title{
Radium isotopes as tracers of iron sources fueling a Southern Ocean phytoplankton bloom
}

\author{
Matthew A. Charette*, Meagan E. Gonneea \\ Department of Marine Chemistry and Geochemistry \\ Woods Hole Oceanographic Institution \\ Woods Hole, Massachusetts 02543
}

\begin{abstract}
Paul Morris, Peter Statham, Gary Fones ${ }^{\dagger}$, Hélène Planquette, Ian Salter, Alberto Naveira Garabato

National Oceanography Centre

Southampton, $U K$
\end{abstract}

Submitted to:

\section{Deep Sea Research II}

September 29, 2006

Revised version: April 3, 2007

In final form: April 24, 2007

Keywords: radium isotopes, iron, productivity, ocean mixing, Southern Ocean

*corresponding author, mcharette@whoi.edu; tel, 508-289-3205; fax, 508-457-2193

${ }^{\dagger}$ now at: School of Earth and Environmental Sciences, University of Portsmouth, Portsmouth, $U K$ 


\begin{abstract}
Elevated levels of productivity in the wake of Southern Ocean island systems are common despite the fact that they are encircled by high nutrient low chlorophyll (HNLC) waters. In the Crozet Plateau region, it has been hypothesized that iron from island runoff or sediments of the plateau could be fueling the austral summer phytoplankton bloom. Here, we use radium isotopes to quantify the rates of surface ocean iron supply fueling the bloom in the Crozet Plateau region. A 1-D eddy-diffusion-mixing model applied to ${ }^{228} \mathrm{Ra}$ profile $\left(\mathrm{t}_{1 / 2}=5.75 \mathrm{yr}\right)$ at a station north of the islands suggested fast vertical mixing in the upper $300 \mathrm{~m}\left(K_{z}=11-100 \mathrm{~cm}^{2} \mathrm{~s}^{-}\right.$ $\left.{ }^{1}\right)$ with slower mixing between 300 and $1000 \mathrm{~m}\left(K_{z}=1.5 \mathrm{~cm}^{2} \mathrm{~s}^{-1}\right)$. This estimate is discussed in the context of $K_{z}$ derived from the CTD/LADCP data. In combination with the dissolved Fe profile at this location, we estimated a vertical flux of between 5.6 and $31 \mathrm{nmol} \mathrm{Fe} \mathrm{m}^{-2} \mathrm{~d}^{-1}$. The cross-plateau gradients in the short-lived radium isotopes, ${ }^{224} \mathrm{Ra}\left(\mathrm{t}_{1 / 2}=3.66 \mathrm{~d}\right)$ and ${ }^{223} \mathrm{Ra}\left(\mathrm{t}_{1 / 2}=\right.$ $11.4 \mathrm{~d})$, yielded horizontal eddy diffusivities $\left(K_{h}\right)$ of $39 \mathrm{~m}^{2} \mathrm{~s}^{-1}$ and $6.6 \mathrm{~m}^{2} \mathrm{~s}^{-1}$, respectively. If we assume that the islands (surface runoff) alone were supplying dissolved Fe to the bloom region, then the flux estimates range from 2.3 to $14 \mathrm{nmol} \mathrm{Fe} \mathrm{m}^{-2} \mathrm{~d}^{-1}$. If the plateau sediments are considered a source of $\mathrm{Fe}$, and conveyed to the bloom region through deep winter mixing combined with horizontal transport, then this flux may be as high as 64 to $390 \mathrm{nmol} \mathrm{Fe} \mathrm{m} \mathrm{d}^{-1}$. Combined, these Fe sources are sufficient to initiate and maintain the annual phytoplankton bloom.
\end{abstract}




\section{Introduction}

An important feature of island systems in the high nutrient low chlorophyll (HNLC) waters of the Southern Ocean is the elevated levels of productivity observed around them and in their wakes during the austral summer (Korb et al., 2004). This "island effect" has been hypothesized to be due to iron release from the island and associated shelf systems into the surrounding waters, thus allowing primary production to occur in this otherwise barren HNLC zone (Blain et al., 2001). In the Kerguelen Islands system very high water column Fe (>10 nM) has been observed close to the islands at the beginning of the austral summer (Bucciarelli et al., 2001), and for the Crozet system later in the year (see Planquette et al., this volume) high values have been observed close to the islands. However the precise release mechanisms and the magnitude of dispersion and fate of any released Fe remains unclear. In terms of lateral dispersion and vertical mixing of Fe containing water into the euphotic zone the use of natural radio-tracers represent a powerful tool to track these island inputs and their dispersion and mixing with adjacent waters.

The large-scale input of radium isotopes along the coastline is akin to a purposeful tracer release, with the short-lived radium isotopes providing the rate of dispersion based on their decay as they mix away from the source. Naturally occurring radium isotopes $\left({ }^{226} \mathrm{Ra}-\mathrm{t}_{1 / 2}=1600\right.$ years, ${ }^{228} \mathrm{Ra}-\mathrm{t}_{1 / 2}=5.75$ years, ${ }^{224} \mathrm{Ra}-\mathrm{t}_{1 / 2}=3.66$ days, and ${ }^{223} \mathrm{Ra}-\mathrm{t}_{1 / 2}=11.4$ days) have been used for decades to quantify lateral mixing processes between shelf waters and the open ocean (Moore et al., 1980; Key et al., 1985; Moore et al., 1995). Until recently, however, radium analyses were primarily restricted to the two longer-lived $\mathrm{Ra}$ isotopes, ${ }^{226} \mathrm{Ra}$ and ${ }^{228} \mathrm{Ra}$, which limited the utility of this tracer quartet to time-scales of months to years. A new technique for measuring the shortlived $\mathrm{Ra}$ isotopes, ${ }^{224} \mathrm{Ra}$ and ${ }^{223} \mathrm{Ra}$, has greatly expanded the power of these tracers to include 
short-term mixing processes on time-scales of days to weeks (Moore and Arnold, 1996; Moore, 2000).

There are two factors that make radium isotopes useful for tracing rates of water movement in the ocean. First, they are produced by decay of particle-bound thorium isotopes in sediments. Therefore, radium isotopes are continually added at ocean boundaries from sediments by both advective (i.e. submarine groundwater discharge) and diffusive processes. Hence, there is a strong source along the coastline and at any sediment-water interface. Secondly, and most importantly, they behave conservatively (on time-scales relative to upper ocean mixing) once released into marine waters; the only processes affecting their distribution are mixing and decay. Thus, radium isotopes, with their shelf-water source and wide-ranging half-lives, are ideally suited for evaluating the source and input rate of iron to Southern Ocean surface water.

Koczy et al. (1957) and Koczy (1958) first recognized the potential of radium isotopes as tracers of ocean mixing processes. The first widespread application was the use of ${ }^{228} \mathrm{Ra}$ during the GEOSECS (Geochemical Ocean Sections) expeditions as a tracer of vertical mixing in the deep ocean (e.g. Kaufman et al., 1973; Sarmiento et al., 1976; Sarmiento et al., 1982) and across the thermocline (e.g. Moore, 1972; Trier et al., 1972, Kaufman et al., 1973). Kaufman et al. (1973) were the first to use ${ }^{228} \mathrm{Ra}$ to calculate horizontal mixing rates away from the coastline. However, Moore (1987) recognized that inputs of ${ }^{228} \mathrm{Ra}$ at the coastline were not in steady state due to seasonal changes in the flux from rivers and estuaries (and more recently submarine groundwater discharge-Moore, 1996). Hence, the assumption of a constant boundary condition (on the time scale of the ${ }^{228}$ Ra half-life) in the model was not satisfied. Fortunately, the two short lived radium isotopes, ${ }^{223} \mathrm{Ra}$ and ${ }^{224} \mathrm{Ra}$, are ideally suited for horizontal mixing studies, their half- 
lives being short enough relative to seasonal changes in their input functions to satisfy the constant boundary condition assumption (Moore, 2000).

The overall goal of this study was to use radium isotopes to identify the rates of supply of iron fueling the bloom in the Crozet Plateau region. We focused our study on evaluating rates of vertical and horizontal Fe input. The vertical source was deep water Fe mixed to the surface via enhanced mixing due to interaction of the Antarctic Circumpolar Current (ACC) or tidal flows with the shallow bathymetry of the plateau. Horizontal sources were thought to be either runoff from the island or diffusive input from plateau sediments carried by subsurface horizontal advection into the bloom region. With this in mind, the paper will focus on two subsets of the Ra data from the Crozex experiment: (1) a vertical Ra profile at station M3 about $60 \mathrm{~km}$ to the north of the islands and (2) a surface water Ra transect from the surf zone of one Crozet island out toward the M3 station. 


\section{Methods}

\subsection{Sample collection}

Samples for radium isotopic analysis were collected aboard the RRS Discovery during two cruises (D285, D286) to the Crozet Plateau region between November 2004 and January 2005. Two types of samples will be discussed in this paper: (1) surface water samples collected from one of two ship based intake systems or by hand (using buckets) when collected from a zodiac during near-island operations, and (2) depth profile samples collected by either OTE bottles on the CTD rosette or by hanging fibers from a sediment trap array.

Water samples $(\sim 150-400 \mathrm{~L})$ for determination of radium isotopes in surface water were collected from either the ship's fire hose system or the non-toxic (science) intake. Samples were filtered and pumped directly into polyethylene barrels where subsamples for ancillary measurements (i.e. salinity, nutrients) were taken. The remaining water was then passed through $\mathrm{MnO}_{2}$-impregnated fibers for extraction of radium isotopes (Moore, 1985).

Surface water Ra samples were originally collected using the ship's fire hose system. However, halfway through the D285 cruise, this intake was determined to be contaminated for the short-lived Ra isotopes, in particular ${ }^{224} \mathrm{Ra}$, presumably from ${ }^{228} \mathrm{Th}$ accumulation throughout the intake plumbing in this poorly flushed system. For the remainder of D285 and all of D286, samples were taken from the ship's non-toxic supply and filtered through a $10 \_\mathrm{m}$ and $1 \_\mathrm{m}$ prefilter. Though the short-lived radium isotope data from the fire hose system was discarded, the long-lived radium isotopes $\left({ }^{226} \mathrm{Ra},{ }^{228} \mathrm{Ra}\right)$ were consistent between the two intake systems and were therefore deemed usable.

A vertical profile of Ra isotopes (and ${ }^{227} \mathrm{Ac}$ ) at the M3 station was obtained using a combination of methods. First, mesh bags containing $\mathrm{MnO}_{2}$-impregnated fibers were attached at 
different depths on the physical instrument mooring at station M3. The mooring was deployed on November 13, 2004 and recovered on January 9, 2005. Then, over the course of the two cruises, which had multiple reoccupations of the M3 station, the CTD rosette was used to obtain $\sim 260 \mathrm{~L}$ samples from the exact depths of the mooring samples. This allowed us to obtain precise ${ }^{226} \mathrm{Ra}$ activities, which were then used to calculate the "effective volume" of seawater collected by the fibers attached to the mooring. From this, ${ }^{228} \mathrm{Ra}$ and ${ }^{227} \mathrm{Ac}$ activities could be calculated for the mooring samples. During the $\sim 2$-month period, the mooring fibers were determined to have effective sample volumes ranging from 5800 to $14,000 \mathrm{~L}$.

\subsection{Sample analysis}

Radium isotopes were counted using gamma spectrometers $\left({ }^{226} \mathrm{Ra},{ }^{228} \mathrm{Ra}\right)$ and alpha scintillation techniques. First, the $\mathrm{MnO}_{2}$-impregnated fibers were rinsed with DI water, partially dried with compressed air, and placed in a scintillation cell attached to a photo multiplier tube which discriminates between the alpha decay of the short-lived daughters of ${ }^{223} \mathrm{Ra}$ and ${ }^{224} \mathrm{Ra}$ via delayed coincidence counting techniques (Moore and Arnold 1996). Due to the short half-life of these isotopes, this technique was performed on-board the vessel. The fibers were stored for several weeks and counted a second time for quantifying the supported activity of ${ }^{224} \mathrm{Ra}$ (from $\left.{ }^{228} \mathrm{Th}\right)$. A final count after $>2$ months was performed for supported ${ }^{223} \mathrm{Ra}$ activity and ${ }^{227} \mathrm{Ac}$ determination. Lastly, the Mn-fibers were ashed at $820^{\circ} \mathrm{C}$ for $16 \mathrm{hr}$ (Charette et al., 2001) and the ash transferred to vials for direct counting on a well-type germanium gamma spectrometer to measure ${ }^{226} \mathrm{Ra}$ and ${ }^{228} \mathrm{Ra}$. All detectors were calibrated using standards prepared in the same geometry as the samples. Uncertainties were typically as follows: $1-3 \%\left({ }^{226} \mathrm{Ra}\right),<10 \%\left({ }^{224} \mathrm{Ra}\right)$, $15-25 \%\left({ }^{223} \mathrm{Ra},{ }^{228} \mathrm{Ra}\right)$. The short-lived radium isotopes are reported as the activity in excess of 
their respective parent isotopes $\left({ }^{227} \mathrm{Ac} \longrightarrow{ }^{223} \mathrm{Ra},{ }^{228} \mathrm{Th} \longrightarrow{ }^{224} \mathrm{Ra}\right)$. The ${ }^{227} \mathrm{Ac}$ data may be used in the future to learn about ocean mixing processes near Crozex. However, ${ }^{227}$ Ac will be most useful in concert with ${ }^{228} \mathrm{Ra}$ measurements, which are at present incomplete due to the extremely low activities observed at this location. 


\section{Results}

The large-scale circulation pattern surrounding the Crozet Plateau are described in detail by Pollard et al. and Read et al., which can be found in this special volume of Deep-Sea Research II. Briefly, the SubAntarctic Front (SAF), a major branch of the ACC, flows anticyclonically around the Del Cano Rise, which is located to the west of the Plateau. This "bending" of the SAF is driven by the bathymetry in this region, and is present year-round. Flow past the two main islands (Fig. 1) is predominantly to the north. In the shadow of the SAF there is a weaker anticyclonic circulation, which in theory allows land and plateau-derived dissolved materials such as iron to accumulate to the north of the islands during the austral winter. A main hypothesis of the CROZEX experiment is that this lateral input of iron from these sources drives the annual phytoplankton bloom in this region.

This paper focuses on two types of samples from the CROZEX experiment: an offshore transect of surface water samples (Table 1) and a vertical profile at one of the major stations (M3) within the bloom region (Table 2). The location of these stations is shown in Fig. 1. Given that the stations in the offshore transect were not along a straight line, the distance offshore was calculated as the linear distance from the surf zone sample (taken as $0 \mathrm{~km}$ ).

\subsection{Comparison of Ra activities with prior measurements in the Southern Ocean}

The ${ }^{226} \mathrm{Ra}$ activities from the surface transect and the upper $300 \mathrm{~m}$ at M3 were typical of Subantarctic Surface Water (SASW) according to the classification of Ku et al. (1970) and Ku and Lin (1976). Below $300 \mathrm{~m}$ at M3, the ${ }^{226}$ Ra activities were characteristic of Antarctic Intermediate Water (AAIW). The $1930 \mathrm{~m}$ sample at M3 could be classified as either Circumpolar Deep Water (CDW) or simply AAIW that had been enriched by ${ }^{226}$ Ra diffusion 
from bottom sediments. Given its relatively short half-life and the minimal interaction of SASW with ocean margin sediments, surface water ${ }^{228} \mathrm{Ra}$ activities were expectedly low for this region of the ocean. Average ${ }^{228} \mathrm{Ra}$ activities for the Antarctic Polar Front of $0.1-0.2 \mathrm{dpm} 100 \mathrm{~kg}^{-1}$ were reported by Kaufman et al. (1973). At $>15 \mathrm{~km}$ from shore, there was essentially no unsupported ${ }^{223} \mathrm{Ra}$ and ${ }^{224} \mathrm{Ra}$. Near island samples, however, showed significant enrichment over the background SASW levels (0.89-4.7 dpm $\left.100 \mathrm{~L}^{-1}\right)$, though the absolute values were low compared with ${ }^{228} \mathrm{Ra}$ in other nearshore regions (e.g. Rama and Moore, 1996; Moore, 1997). To the best of our knowledge, these are the first measurements of ${ }^{223} \mathrm{Ra}$ and ${ }^{224} \mathrm{Ra}$ within the ACC, thus we have no prior studies for this ocean basin with which to compare our values. However, like ${ }^{228} \mathrm{Ra}$, the near shore surface samples were on the low end of typical coastal values (e.g. Moore, 2000; Charette et al., 2001), but in line with other volcanic island systems (e.g. Hawaii, Mauritius), which appear to be minor sources of Ra isotopes to the ocean (Charette, unpub. data; Gonneea, unpub. data).

\subsection{Trends in Ra with depth and distance from the Crozet Islands}

The offshore transect consisted a series of six stations between the surf zone within the Baie du Marin on Ile de la Possession to $\sim 15 \mathrm{~km}$ offshore. The salinity of the surf zone sample was $\sim 22$, which suggests that the enrichments in silicate, ${ }^{224} \mathrm{Ra},{ }^{223} \mathrm{Ra}$, and ${ }^{228} \mathrm{Ra}$ were all due to sediment-water interactions on the island itself. Radium-226 was only moderately enriched (13.1-13.2 vs. 11.4-12 dpm $100 \mathrm{~L}^{-1}$ ) relative to the offshore samples. The relative decrease with distance from shore for the remaining three $\mathrm{Ra}$ isotopes is indicative of their much shorter halflives relative to ${ }^{226} \mathrm{Ra}$. A number of the samples did not have sufficient volume for detecting 
${ }^{228} \mathrm{Ra}$. Of the two nearshore samples where ${ }^{228} \mathrm{Ra}$ was detectable, the relatively large difference is due to dilution (not decay) with ${ }^{228}$ Ra depleted ACC waters (Kaufman et al., 1973).

The vertical profile at station M3 covered 10 depths between $50 \mathrm{~m}$ and $1930 \mathrm{~m}$ (within $\sim 100 \mathrm{~m}$ of the bottom). Radium-226 was essentially constant throughout the water column, except for a low value at $100 \mathrm{~m}$ and a $20 \%$ enrichment in the near bottom samples (Fig. 2a). The low value at $100 \mathrm{~m}$ could be due to either a low recovery on the $\mathrm{MnO}_{2}$ fiber or the presence of subantarctic surface water. Given the low salinity of the sample and the fact that this station is a significant distance from the polar frontal zone, the former explanation is the most likely one. Radium-228 was enriched in the upper water column to $500 \mathrm{~m}$, below detection in the mid-water between 900 and $1300 \mathrm{~m}$, and enriched in the near bottom samples (Fig. 2b). The shape of the ${ }^{228} \mathrm{Ra}$ profile (decreasing from the top down and from the bottom up) is indicative of the submarine sediment source at the boundaries (upper ocean) and the abyssal ocean. Hence, the mid water column is depleted in ${ }^{228}$ Ra relative to surface and deep waters due to slow downward and upward vertical mixing from these two sources. 


\section{Discussion}

\subsection{Determination of horizontal and vertical mixing rates using Ra isotopes}

If horizontal and vertical dispersion of a radium isotope can be approximated as a diffusive process (rather than advective), a simple one-dimensional diffusion model can be written as:

$$
\frac{d A}{d t}=K_{h} \frac{\partial^{2} A}{\partial x^{2}}-\lambda A
$$

where $A$ is the radium isotope activity, $K_{h}$ is the horizontal eddy diffusion coefficient, $x$ is the distance offshore, and $\lambda$ is the decay constant for the isotope of interest. At steady-state, eqn. (1) becomes:

$$
A_{x}=A_{0} \cdot \exp \left[-x \sqrt{\frac{\lambda}{K_{h}}}\right]
$$

where $A_{x}$ is the activity at distance $x$ from the coast and $A_{0}$ is the radium activity at the boundary $(x=0)$. In this case, $K_{h}$ can be calculated from slope $(m)$ of a plot of $\ln \left({ }^{223} \mathrm{Ra}\right)$ or $\ln \left({ }^{224} \mathrm{Ra}\right) \mathrm{vs}$. distance offshore $\left(K_{h}=\lambda / \mathrm{m}^{2}\right)$. The rates of horizontal diffusion for both isotopes should be equal, if the system is in steady state on the time-scales of both ${ }^{223} \mathrm{Ra}$ and ${ }^{224} \mathrm{Ra}$. Lastly, the surface ocean layer must be isolated (via a strong pycnocline) from sedimentary input along the transect of interest.

Though the model described by eqn. (1) does not include a term for advection, the resulting $K_{h}$ will in most cases still provide an accurate estimate of the offshore mixing rate 
presuming there is a reasonable fit to the Ra data. In this way, the Ra-derived $K_{h}$ does not imply that mixing is purely through eddy diffusion, making it an "effective" horizontal eddy diffusivity that can be used to quantify the offshore transport of other elements with a similar (sedimentary) source.

Given that diapycnal mixing is a significantly slower process, the longer-lived ${ }^{228} \mathrm{Ra}$ must be used to evaluate mixing across the thermocline. In this application, the equation (2) takes the same form except that $x$ is replaced with $z$ (depth) and $K_{z}$ will be used to represent the vertical eddy diffusion coefficient. The same assumption of a constant source (at the top of the thermocline) applies here as well. Finally, one must assume that lateral input of ${ }^{228} \mathrm{Ra}$ below the surface mixed layer is not taking place.

\subsection{Horizontal flux of island-derived Fe inferred from the short-lived Ra isotope distribution}

To investigate whether or not runoff from the Crozet Islands was a significant source of Fe to the bloom region, we analyzed Ra isotopic activities in a series of stations with increasing distance from the island. Then, using equation (2) to calculate $K_{h}$ and an estimate of the dissolved Fe gradient along the same transect, we were able to estimate the island-derived $\mathrm{Fe}$ source.

Figures $3 \mathrm{a}$ and $4 \mathrm{a}$ show the ${ }^{223} \mathrm{Ra}$ and ${ }^{224} \mathrm{Ra}$ gradients along the $15 \mathrm{~km}$ transect. Both display a near-exponential decrease with distance from shore, suggesting that our assumption of eddy diffusion-dominated mixing (versus onshore or offshore advection) is a good one (Moore, 2000). The slope ( $\ln$ transformed) in the Ra data as shown in Figs. $3 \mathrm{~b}$ and $4 \mathrm{~b}$ can be used to estimate $K_{h}$ along this transect. The ${ }^{223} \mathrm{Ra}$ gradient corresponded to a $K_{h}$ of $6.6 \mathrm{~m}^{2} \mathrm{~s}^{-1}$ while the ${ }^{224} \mathrm{Ra}$ gradient produced a $K_{h}$ of $39 \mathrm{~m}^{2} \mathrm{~s}^{-1}$. Okubo (1971) demonstrated that $K_{h}$ increased with 
increasing length scale; according to this relationship, the factor of $\sim 3$ lower half-life for ${ }^{224} \mathrm{Ra}$ would in theory lead to a lower $K_{h}$ estimate for this isotope. Hence, the difference in these estimates may not be attributed to the different length-scale integrals of the isotopes. The discrepancy is more likely related to the data gap between $\sim 3$ and $11 \mathrm{~km}$ and the non-shore perpendicular nature of the transect, which creates some uncertainty about mixing within this zone. For example, the slope of the ln-transformed ${ }^{224}$ Ra data suggests a dual-mixing regime: slow mixing in the nearshore $(0-3 \mathrm{~km})$ zone followed by more rapid mixing offshore to $15 \mathrm{~km}$. Regardless, the Ra-derived estimates of $K_{h}$ represent extremely slow offshore mixing when compared with other coastal regions. However, these slow mixing rates are supported by the long residence time of water ( $\sim 60$ days) to the north of the islands as estimated from Argo floats (Pollard et al., this issue; Venables et al., this issue).

From the dissolved Fe data of Planquette et al. (this issue), we calculate an offshore Fe gradient along the same transect of $0.070 \mathrm{nmol} \mathrm{Fe} \mathrm{m}^{-3} \mathrm{~m}^{-1}$. The product of this gradient and the ${ }^{223} \mathrm{Ra}$-derived $K_{h}$ is $0.46 \mathrm{nmol} \mathrm{m} \mathrm{m}^{-2}$ or $40 \mu \mathrm{mol} \mathrm{m} \mathrm{m}^{-2} \mathrm{~d}^{-1}$. To estimate the cumulative effect of the Fe flux from the islands on the entire bloom region we assume that this process is occurring over: (1) a total shoreline length of $75 \mathrm{~km}$ (determined from cumulative circumference of the three islands) (2) a mixed layer depth of $70 \mathrm{~m}$ (average during the study period). Thus, the total dissolved Fe flux originating from the islands is $210 \mathrm{~mol} \mathrm{Fe}^{-1}$. Normalized to a bloom area of approximately $90,000 \mathrm{~km}^{2}$ (Venables et al., this issue), the Fe flux becomes $\sim 2.3 \mathrm{nmol} \mathrm{m}^{-2} \mathrm{~d}^{-1}$. Using the ${ }^{224}$ Ra-derived $K_{h}$ of $39 \mathrm{~m}^{2} \mathrm{~s}^{-1}$, the flux would be $14 \mathrm{nmol} \mathrm{m}{ }^{-2} \mathrm{~d}^{-1}$.

If we assume a similar dissolved Fe gradient is not derived from the island per se, but by sediment-water interactions on the entire plateau, then we might arrive at a different conclusion. This assumption is reasonable given that the blooms usually do not form on the plateau itself but 
at the edge (Pollard et al., this issue). With a radius of $\sim 100 \mathrm{~km}$, the plateau would have a circumference of $\sim 600 \mathrm{~km}$, producing fluxes a factor of eight higher than above $\left(18-110 \mathrm{nmol} \mathrm{m}^{-}\right.$ $\left.{ }^{2} \mathrm{~d}^{-1}\right)$. Assuming that this process is enhanced during deep winter mixing, when mixed layer depths can reach $250 \mathrm{~m}$ (see section 4.3.), pre-bloom fluxes could be higher by an additional factor of 3-4 (64-390 $\left.\mathrm{nmol} \mathrm{m}^{-2} \mathrm{~d}^{-1}\right)$.

These estimates are not without limitation. Unlike Ra, iron is not a conservative tracer. Therefore, scavenging and loss of dissolved Fe onto sinking particles before most of the iron can be distributed to the entire bloom region may make this value an overestimate. Also, concentrations measured along our single transect may not be representative of the entire coastline of the Crozet Islands. Lastly, the short-lived Ra data suggest that mixing may not be constant along the entire $15 \mathrm{~km}$ transect. Given that we do not have detailed Fe gradients along both "regimes", it is not possible to evaluate the Fe flux for each case. Instead, we have taken the approach to evaluate upper and lower limit Fe fluxes based on mixing derived from each short lived $\mathrm{Ra}$ isotope.

\subsection{Entrainment of deep-water Fe during turbulent vertical mixing}

Given a sufficient rate of vertical mixing, dissolved Fe from below the euphotic zone is a potential source of iron to the bloom region. To evaluate this flux, various model $K_{z}$ fits (using equation 2) were applied to a vertical profile of ${ }^{228} \mathrm{Ra}$ along with an average dissolved $\mathrm{Fe}$ gradient across the same depth interval.

Figure 5 shows the results of fitting equation 2 to the ${ }^{228}$ Ra profile at station M3 under several different mixing scenarios. The best-fit curve to the profile was $11 \mathrm{~cm}^{2} \mathrm{~s}^{-1}$. This assumes

that the sole source (with a steady state activity over the time-scale of its half-life) of ${ }^{228} \mathrm{Ra}$ is the 
surface mixed layer and therefore that vertical mixing and decay are the only processes controlling its distribution. However, the degree of mixing is not necessarily constant across the entire depth range. Thus, the more likely interpretation of this ${ }^{228} \mathrm{Ra}$ profile is a dual mixing regime: fast mixing in the upper $300 \mathrm{~m}$ with slower mixing below this depth to $1000 \mathrm{~m}$. For the upper $300 \mathrm{~m}, K_{z}$ curves between 11 and $100 \mathrm{~cm}^{2} \mathrm{~s}^{-1}$ could be fitted to the profile. However, the uncertainty on the measurements is such that they are essentially overlapping. A constant value over this depth range is certainly plausible given that winter time mixed layer depth has been estimated at $\sim 150-250 \mathrm{~m}$ (Venables et al., this issue). Below $300 \mathrm{~m}$ and above $1000 \mathrm{~m}$ the bestfit $K_{z}$ is $1.5 \mathrm{~cm}^{2} \mathrm{~s}^{-1}$. If the actual wintertime mixed layer depth was closer to the $150 \mathrm{~m}$ estimate, subsurface advective input of ${ }^{228} \mathrm{Ra}$ from sediment-water interaction on the Crozet Plateau could also produce the observed profile. Given that the 11 and $100 \mathrm{~cm}^{2} \mathrm{~s}^{-1}$ model fits assume a constant source to the upper $50 \mathrm{~m}$, such a process would result in an overestimate of the $K_{z}$.

The technique of Polzin et al. (2002) to quantify the rate of mixing due to internal wave breaking was also used to estimate $K_{z}$ from the CTD / LADCP data at station M3 (Fig. 6). A detailed account of the technique and its implementation can be found in Naveira Garabato et al. (2004). In general, the $K_{z}$ increased with increasing depth; for 50-300 m, $K_{z}$ ranged from 0.34$0.41 \mathrm{~cm}^{2} \mathrm{~s}^{-1}$ while for $300-1000 \mathrm{~m}$ it was $0.35-0.66 \mathrm{~cm}^{2} \mathrm{~s}^{-1}$. These results are consistent with the Ra-derived estimate of $K_{z}$ below $300 \mathrm{~m}$ (within the measurement uncertainty), but are about 1-2 orders of magnitude lower than the upper ocean estimate. Given that (1) the near surface layer in the Southern Ocean is dynamic environment on seasonal time scales, (2) that the Ra method integrates over a much longer time-scale than the LADCP method, and (3) the 1-D Ra estimate may be influenced by horizontal advection, these differences are not entirely surprising. Also, though this comparison does not rule out fluxes on the mesoscale, the flow regime in this region 
is generally weak (Pollard et al., this issue), unlike the Scotia Sea where strong currents sweep through the region (Naveira Garabato et al., 2004). Differences in tides and topographic configuration between these two regions may also play a role. For the deeper layer, the excellent agreement between the two approaches is encouraging.

The ${ }^{228}$ Ra estimates of $K_{z}$ in combination with the dissolved Fe profile data of Planquette et al. (this issue) allow us to make an estimate of the contribution of Fe to the bloom region from below. For the upper $300 \mathrm{~m}$ "fast mixing" $\left(11 \mathrm{~cm}^{2} \mathrm{~s}^{-1}\right)$ scenario and an assumed dissolved $\mathrm{Fe}$ gradient over this depth range of $0.64 \mathrm{nmol} \mathrm{Fe} \mathrm{m}^{-3} \mathrm{~m}^{-1}(0.15 \mathrm{nM} @ 5 \mathrm{~m}, 0.34 \mathrm{nM} @ 300 \mathrm{~m})$,we estimate a vertical flux of $61 \mathrm{nmol} \mathrm{Fe} \mathrm{m}^{-2} \mathrm{~d}^{-1}$. For the situation where relatively slow mixing between 1000 and $300 \mathrm{~m}\left(1.5 \mathrm{~cm}^{2} \mathrm{~s}^{-1}\right.$, dissolved Fe gradient of $\left.0.43 \mathrm{nmol} \mathrm{m}{ }^{-3} \mathrm{~m}^{-1}\right)$ combines with deep winter mixing to $150-250 \mathrm{~m}$, the dissolved Fe flux would be $5.6 \mathrm{nmol} \mathrm{Fe} \mathrm{m}^{-2} \mathrm{~d}^{-1}$. 


\section{Conclusions}

Here, we have quantified two potential sources of dissolved Fe to the bloom region north of the Crozet Islands/Plateau. Horizontal mixing of island-derived dissolved Fe was estimated to contribute 2.6-14 nmol Fe m $\mathrm{m}^{-2} \mathrm{~d}^{-1}$, while inclusion of the entire plateau as an Fe source yielded rates of 18-390 nmol Fe m $\mathrm{m}^{-2} \mathrm{~d}^{-1}$. Vertical mixing supplied an additional 5.6-61 $\mathrm{nmol} \mathrm{Fe} \mathrm{m} \mathrm{m}^{-2} \mathrm{~d}^{-1}$. Based on literature estimates of the cellular N:Fe requirement of phytoplankton and ${ }^{15} \mathrm{~N}$ new production estimates, Lucas et al. (this issue) determined that between 25 and $1000 \mathrm{nmol} \mathrm{Fe} \mathrm{m}{ }^{-2}$ $\mathrm{d}^{-1}$ was required to sustain the bloom. Thus, the sum of our estimates falls within the range of cellular Fe requirement.

Other sources of Fe not evaluated by this study include atmospheric deposition (100 nmol Fe $\mathrm{m}^{-2} \mathrm{~d}^{-1}$; see Planquette et al. this volume), subsurface lateral input of dissolved Fe, and recycling within the mixed layer. Particulate Fe, which was recently hypothesized to be the driver of a wintertime phytoplankton bloom in the HNLC northeast Pacific Ocean (Lam et al., 2006), may also play a role. Therefore, sources in addition to the lateral and vertical mixing will augment the supply of Fe and add to the Fe inventory in waters to the north of the islands over the year. However, the use of $\mathrm{Ra}$ isotopes has shown that the vertical and horizontal advection alone can provide enough Fe to sustain the bloom. 


\section{Acknowledgements}

The authors would like to thank the captain, officers, engineers, technicians and crew of RRS Discovery for their assistance. Gideon Henderson, Raymond Pollard (Guest Editor), and one anonymous reviewer provided comments that greatly improved the manuscript. This work was funded by grants from the Natural Environment Research Council [NE/B502844/1] and the National Science Foundation (ANT-0443869 to M.A.C). 


\section{References}

Blain, S., Treguer, P., Belviso, S., Bucciarelli, E., Denis, M., Desabre, S., , Fiala, M., Jezequel, V. M., Le Fevre, J., Mayzaud, P., Marty, J.-C., Razouls, , S. and . 2001. A biogeochemical study of the island mass effect in the context of the iron hypothesis: Kerguelen Islands, Southern Ocean. Deep-Sea Res., 48: 163-187.

Bucciarelli, E., Blain, S., Treguer, P., 2001. Iron and manganese in the wake of the Kerguelen Islands (Southern Ocean). Mar. Chem., 73: 21-36.

Charette, M.A., Buesseler, K.O. and Andrews, J.E., 2001. Utility of radium isotopes for evaluating the input and transport of groundwater-derived nitrogen to a Cape Cod estuary. Limnology and Oceanography, 46(2): 465-470.

Fung, I.Y., S. K. Meyn, I. Tegen, S. C. Doney, J. G. John, and J. K. B. Bishop, 2000. Iron supply and demand in the upper ocean. Global Biogeochem. Cyc., 14: 281-295.

Kaufman, A., R.M. Trier, W.S. Broecker and H.W. Feely, 1973. Distribution of Ra-228 in the world ocean. J. Geophys. Res, 78: 8827-8849.

Key, R.M., R.F. Stallard, W.S. Moore, and J.L. Sarmiento, 1985. Distribution and flux of ${ }^{226}$ Ra and ${ }^{228} \mathrm{Ra}$ in the Amazon River estuary. J. Geophys. Res., 90(C4): 6995-7004.

Koczy, F.F., E. Picciotto, G. Poulaert and S. Wilgain, 1957. Mésure des isotopes du thorium dans l'eau de mer. Geochim. Cosmochim. Acta, 11: 103-129.

Koczy, F.F., 1958. Natural radium as a tracer in the ocean, 2nd U. N. Int'l. Conf. Peaceful Uses Atom Energy, Geneva, pp. 351-357.

Korb, R.E., M. J. Whitehouse, P. Ward. , 2004. SeaWIFS in the southern ocean: spatial and temporal variability in phytoplankton biomass around South Georgia. Deep-Sea Res. II 51: 99-116.

Ku, T.L., Y.H. Li, G.G. Mathieu and H.K. Wong, 1970. Radium in the Indian-Antarctic Ocean south of Australia. J. Geophys. Res, 75: 5286-5292.

Ku, T.L. and M.C.Lin., 1976. ${ }^{228}$ Ra distribution in the Antarctic Ocean. Earth Planet. Sci. Lett., 32: $236-248$.

Lam, P. J., J. K. B. Bishop, C. C. Henning, M. A. Marcus, G. A. Waychunas, and I. Y. Fung., 2006. Wintertime phytoplankton bloom in the subarctic Pacific supported by continental margin iron. Global Biogeochem. Cycles, 20: GB1006.

Moore, W.S., 1972. Radium-228: Application to thermocline mixing studies. Earth Planet. Sci. 
Lett., 16: 421-422.

Moore, W.S., H.W. Feely, and Y.-H. Li, 1980. Radium isotopes in subarctic waters. Earth Planet. Sci. Lett., 49: 329-340.

Moore, W.S., 1987. Radium 228 in the South Atlantic Bight. J. Geophys. Res., 92(C5): 51775190.

Moore, W.S., H. Astwood, and C. Lindstrom, 1995. Radium isotopes in coastal waters on the Amazon shelf. Geochim. Cosmochim. Acta, 59(20): 4285-4298.

Moore, W.S., 1996. Large groundwater inputs to coastal waters revealed by ${ }^{226} \mathrm{Ra}$ enrichments. Nature, 380: 612-614.

Moore, W.S., and R. Arnold, 1996. Measurement of ${ }^{223} \mathrm{Ra}$ and ${ }^{224} \mathrm{Ra}$ in coastal waters using a delayed coincidence counter. J. Geophys. Res., 101(C1): 1321-1329.

Moore, W.S., 1997. High fluxes of radium and barium from the mouth of the GangesBrahmaputra River during low river discharge suggest a large groundwater source. Earth Planet. Sci. Lett., 150: 141-150.

Moore, W.S., 2000. Determining coastal mixing rates using radium isotopes. Cont. Shelf Res., 20: 1993-2007.

Naveira Garabato, A.C., K. L. Polzin, B. A. King, K. J. Heywood and M. Visbeck, 2004. Widespread intense turbulent mixing in the Southern Ocean. Science, 303: 210-213.

Okubo, A., 1971. Oceanic diffusion diagrams. Deep-Sea Res., 18: 789-802.

Polzin, K., E. Kunze, J. Hummon and E. Firing, 2002. The finescale response of lowered ADCP velocity profiles. J. Atmos. Oceanic Tech., 19: 205-224.

Rama, and W.S. Moore, 1996. Using the radium quartet for evaluating groundwater input and water exchange in salt marshes. Geochim. Cosmochim. Acta, 60(23): 4645-4652.

Sarmiento, J.L., H.W. Feely, W.S. Moore, A.E. Bainbridge and W.S. Broecker, 1976. he relationship between vertical eddy diffusion and buoyancy gradient in the deep sea. Earth Planet. Sci. Lett., 32: 357-370.

Sarmiento, J.L., C.G.H. Rooth, and W.S. Broecker, 1982. Radium 228 as a tracer of basin wide processes in the abyssal ocean. J. Geophys. Res., 87(C12): 9697-9698.

Trier, R.M., W.S. Broecker, and H.W. Feely, 1972. Radium-228 profile at the second GEOSECS intercalibration station, 1970, in the North Atlantic. Earth Planet. Sci. Lett., 16: 141-145. 
Table 1. Radium isotopes and ancillary data from the off-island transect.

\begin{tabular}{|c|c|c|c|c|c|c|}
\hline $\begin{array}{c}\text { Distance } \\
\text { Offshore }(\mathrm{km})\end{array}$ & Salinity & $\begin{array}{c}\text { Silicate } \\
\left.(\mu \mathrm{mol} \mathrm{L})^{-1}\right)\end{array}$ & ${ }^{224} \mathrm{Ra}_{\mathrm{ex}}$ & $\begin{array}{r}{ }^{223} \mathrm{Ra}_{\text {ex }} \\
\quad(\mathrm{d} \\
\end{array}$ & ${ }^{226} \mathrm{Ra}$ & ${ }^{228} \mathrm{Ra}$ \\
\hline 0.0 & 21.924 & 32.830 & 4.7 & 0.520 & 13.1 & 4.1 \\
\hline 1.3 & 32.000 & 17.080 & 2.1 & 0.116 & 13.2 & B.D.L. \\
\hline 2.6 & 33.900 & 2.320 & 0.31 & 0.042 & 11.7 & B.D.L. \\
\hline 11.2 & 33.839 & 2.860 & 0.44 & 0.019 & 12.0 & 0.89 \\
\hline 12.5 & 33.821 & 4.160 & 0.14 & 0.002 & $7.86^{*}$ & B.D.L. \\
\hline 14.7 & 33.808 & 4.520 & 0.034 & B.D.L. & 11.4 & B.D.L. \\
\hline
\end{tabular}

B.D.L. $=$ below detecton limit

*Apparent low collection efficiency on $\mathrm{MnO}_{2}$ fiber 
Table 2. Radium isotopes and ancillary data from the station M3 profile.

\begin{tabular}{ccccc}
\hline $\begin{array}{c}\text { Depth } \\
(\mathrm{m})\end{array}$ & Salinity & $\begin{array}{c}\sigma_{\mathrm{t}} \\
\left(\mathrm{kg} \mathrm{m}^{-3}\right)\end{array}$ & $\begin{array}{c}{ }^{226} \mathrm{Ra} \\
\left(\mathrm{dpm} 100 \mathrm{~L}^{-1}\right)\end{array}$ \\
\hline 50 & 33.855 & 26.873 & 13.9 & 0.055 \\
100 & 33.959 & 26.999 & 9.4 & 0.058 \\
150 & 33.933 & 26.999 & 12.5 & 0.075 \\
200 & 33.964 & 27.059 & 12.0 & 0.046 \\
300 & 34.051 & 27.141 & 11.4 & 0.051 \\
500 & 34.244 & 27.317 & 13.7 & 0.025 \\
904 & 34.544 & 27.567 & 13.7 & B.D.L. \\
1307 & 34.690 & 27.700 & 13.1 & B.D.L. \\
1687 & 34.744 & 27.762 & 12.5 & 0.033 \\
1930 & 34.760 & 27.788 & 15.2 & 0.048 \\
\hline
\end{tabular}

B.D.L. $=$ below detecton limit 


\section{Figure Captions}

Figure 1. Map showing radium station locations relative to the Crozet Islands and Plateau.

Figure 2. Depth profiles of ${ }^{226} \mathrm{Ra}$ (a) and ${ }^{228} \mathrm{Ra}$ (b) at station M3. The bottom depth at this station is indicated by a hatched line in each plot.

Figure 3. Off-island ${ }^{223}$ Ra transect with (a) activity versus distance from shore and (b) ln transformed ${ }^{223} \mathrm{Ra}$ with slope used to estimate $K_{h}$.

Figure 4. Off-island ${ }^{224} \mathrm{Ra}$ transect with (a) activity versus distance from shore and (b) ln transformed ${ }^{224} \mathrm{Ra}$ with slope used to estimate $K_{h}$.

Figure 5. Model estimates of $K_{z}$ fitted to the ${ }^{228}$ Ra profile at station M3.

Figure 6. $K_{z}$ due to internal wave breaking derived from CTD / LADCP finestructure data, with a nominal uncertainty of a factor of 3 . The ${ }^{228}$ Ra-derived $K_{z}$ estimate for $300-1000 \mathrm{~m}$ is presented for comparison. 


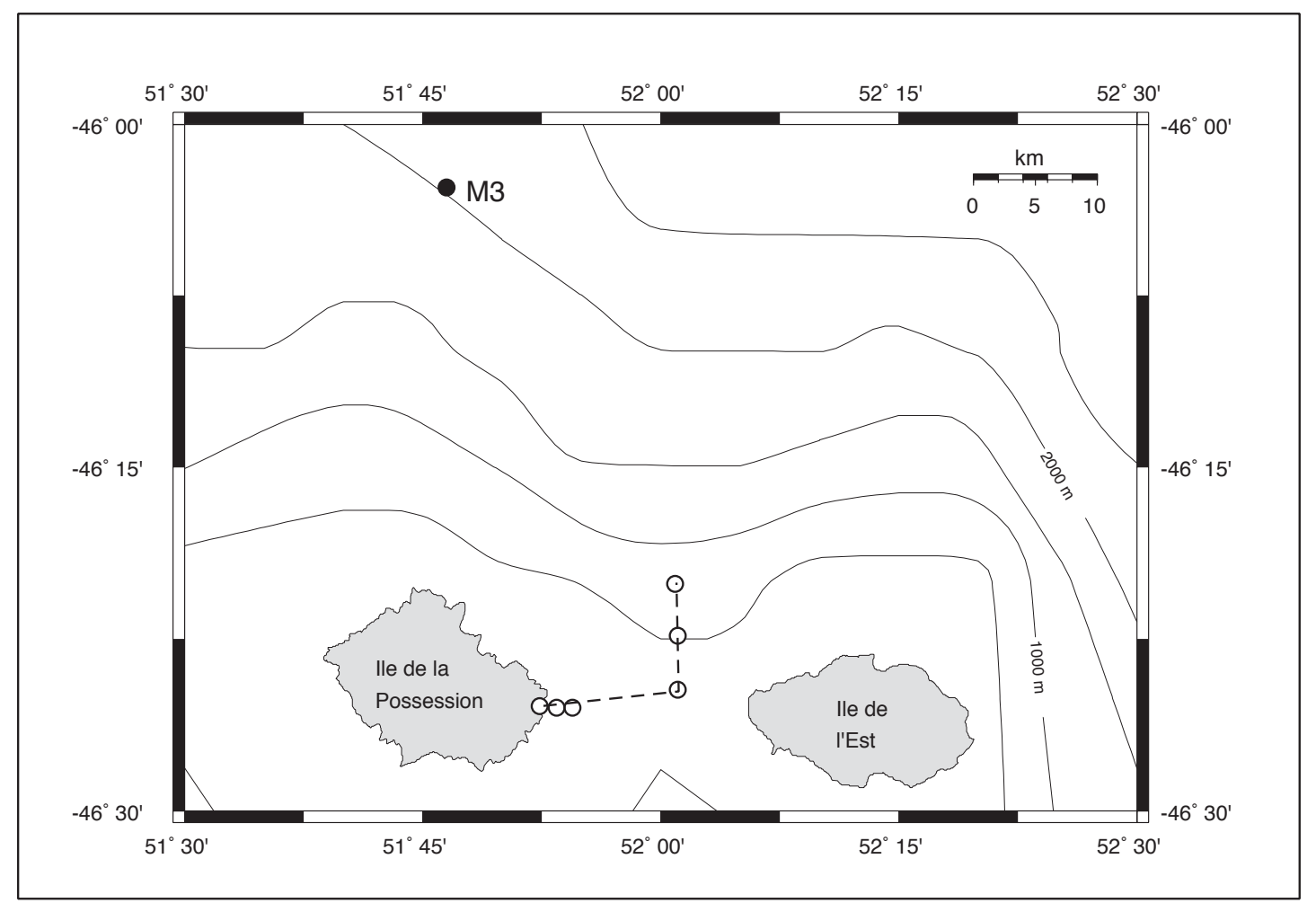




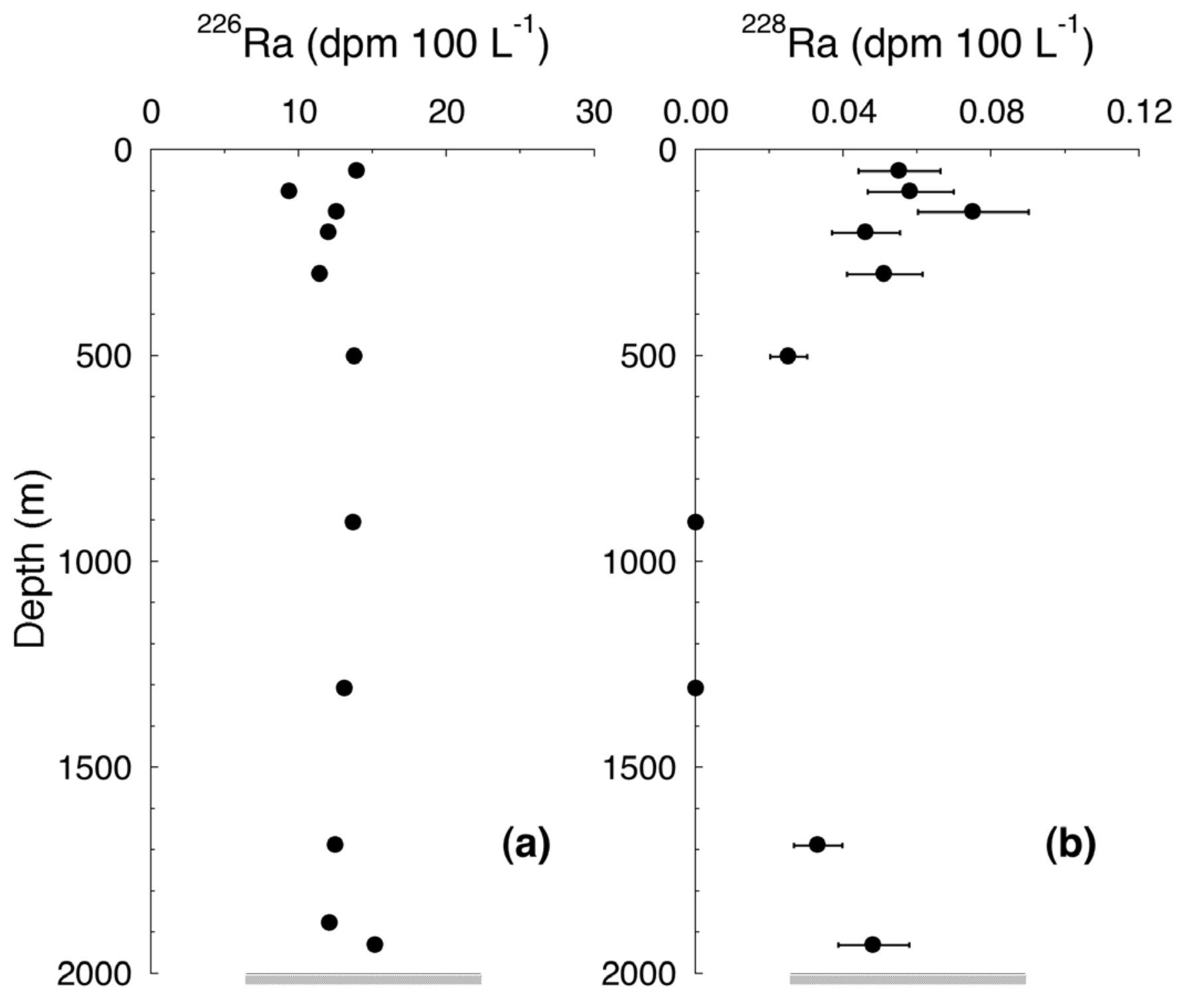



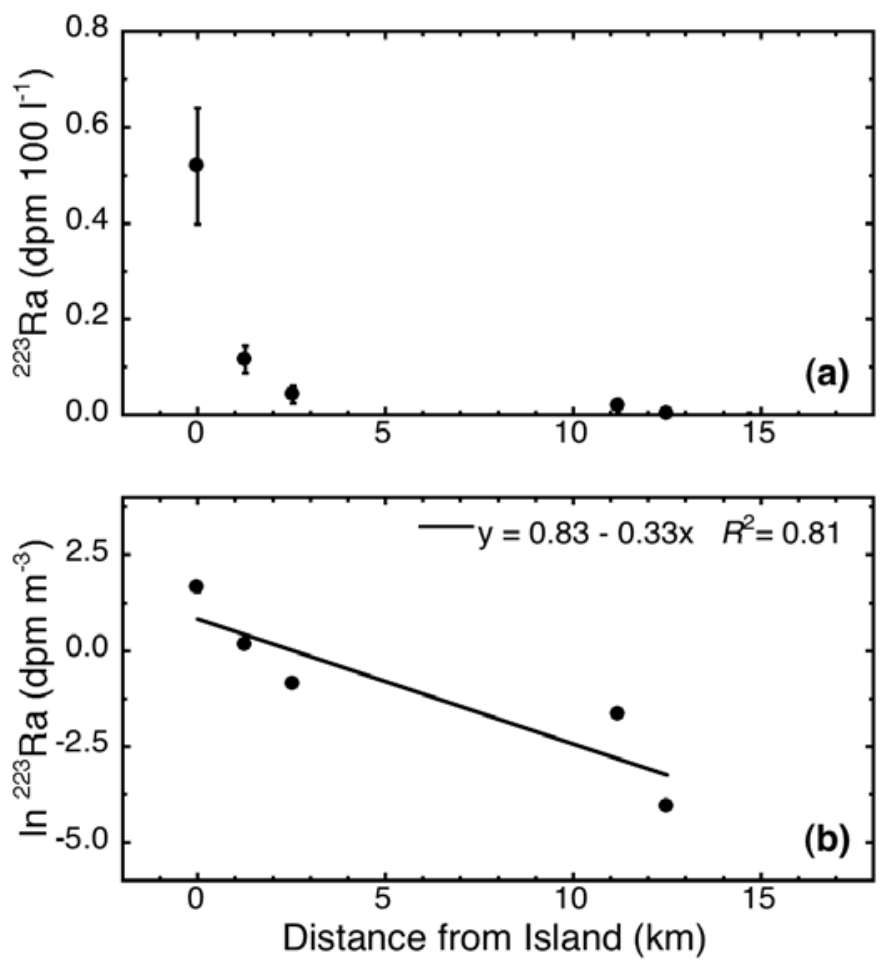

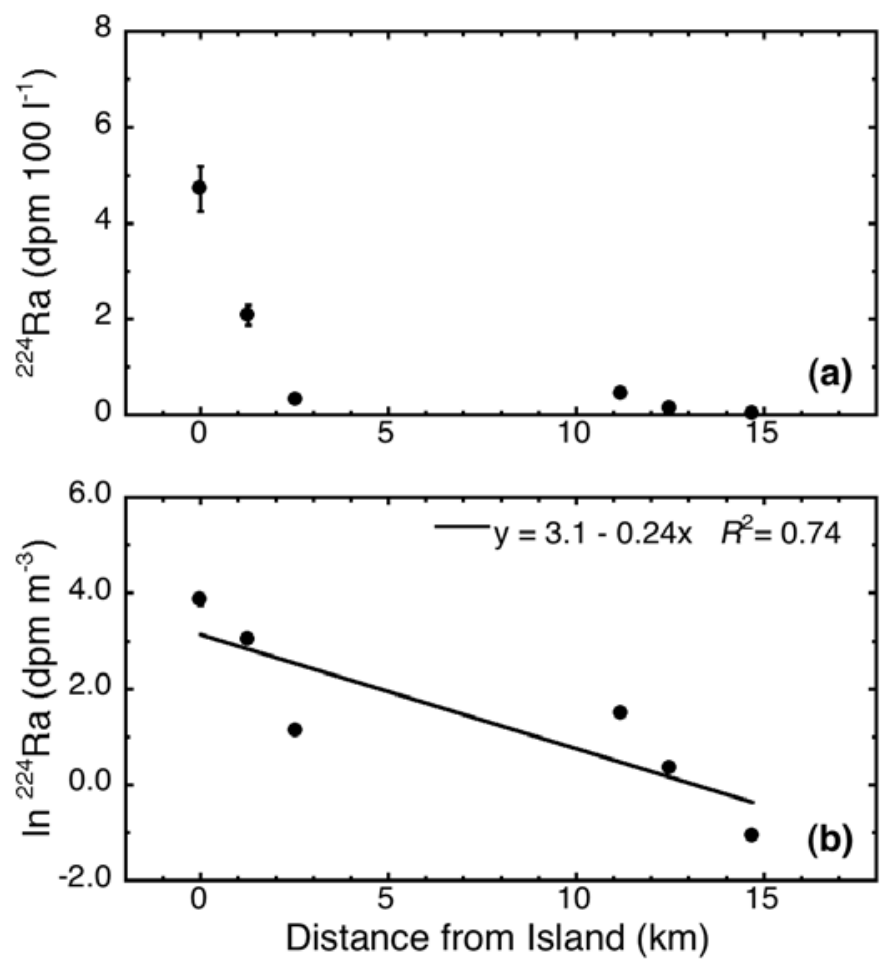


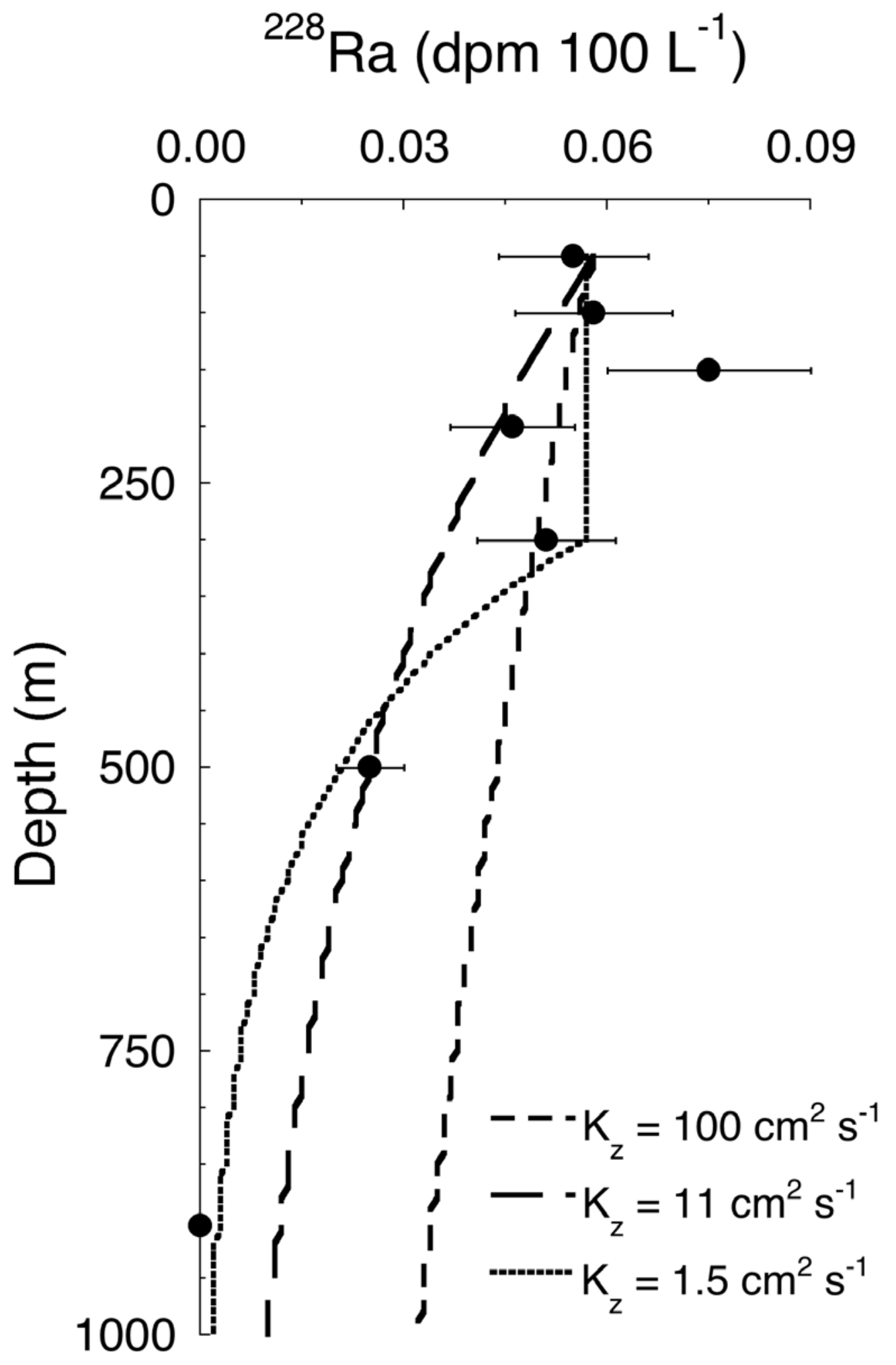




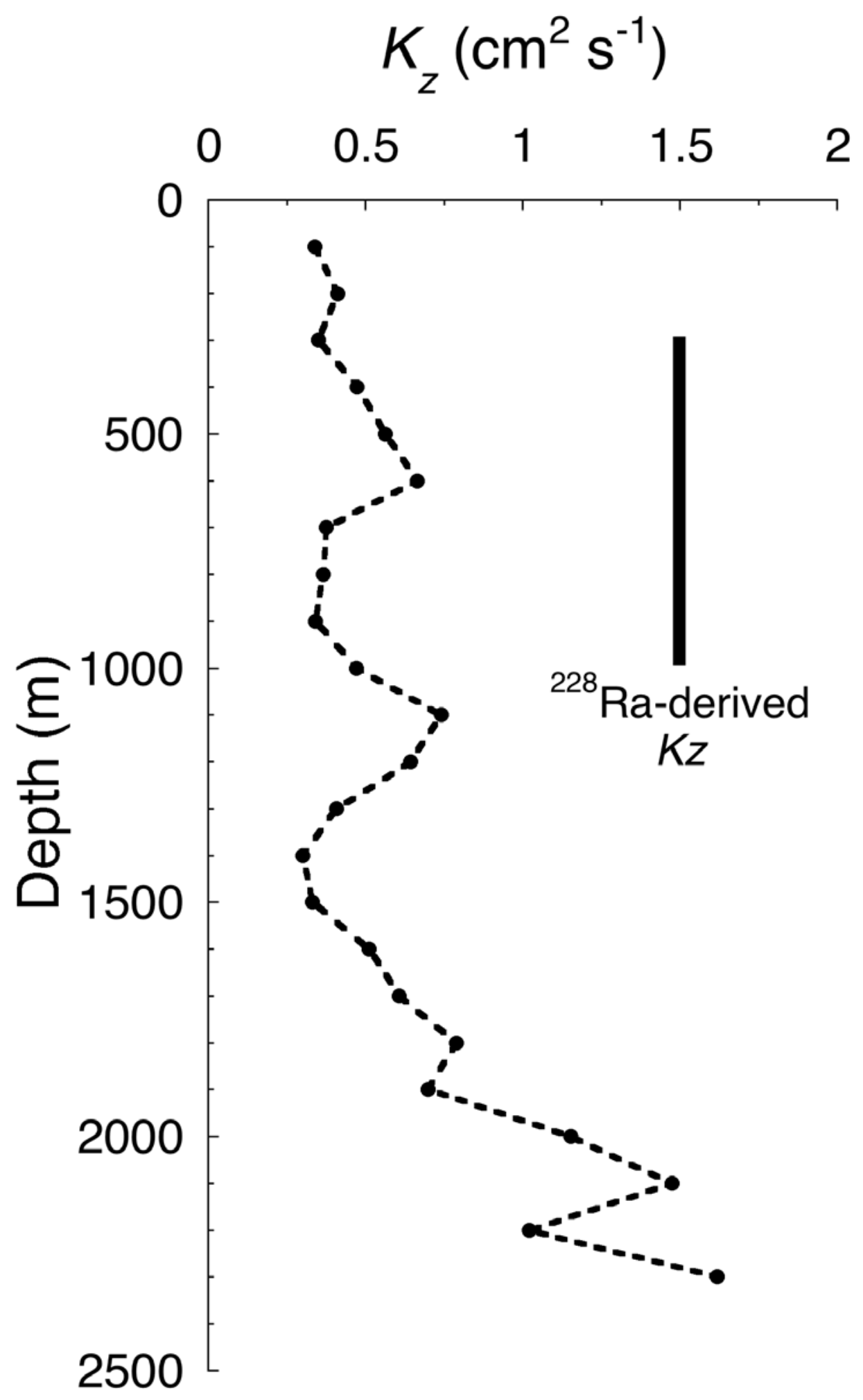

